\title{
Disparities in Life Expectancy Across US Counties Linked to County Social Factors, 2009 Community Health Status Indicators (CHSI)
}

\author{
Benem-Orom Davids • Sonja Suzzete Hutchins • \\ Camara P. Jones • Jessie R. Hood
}

Received: 12 August 2013 / Accepted: 26 November 2013 / Published online: 10 January 2014

(C) Cobb/NMA Health Institute 2014

\begin{abstract}
Objectives In response to a National Healthy People 2020 goal to create social environments to improve health, we examined US community health status by social factors to identify opportunities for health improvement. County-level relationships between life expectancy and known social determinants of health were assessed.

Methods An ecological study of all 3,141 US counties or equivalents using 2009 Community Health Status Indicators dataset was conducted. We examined health status and social indicators across counties and correlation of average life expectancy with educational, income, and racial indicators.

Results Life expectancy varied across US counties (median, 77 years; range, 67-81) and was negatively correlated with percentages of residents living below the federal poverty level $(r=-0.65 ; P<0.05)$, of adults aged $\geq 25$ years without a high school diploma $(r=-0.64 ; P<0.05)$, and of African-American residents $(r=-0.56 ; P<0.05)$. By contrast, life expectancy positively correlated with percentage of White-American residents $(r=0.51 ; P<0.05)$. Correlations persisted across counties with varying poverty and educational attainment; strongest correlations found in counties with largest percentage of residents in poverty or adults with no high school diploma.

Conclusions Life expectancy across US counties is moderately to strongly linked with county poverty, educational attainment, and racial composition. Counties with the longest life expectancy need further examination to identify their effective
\end{abstract}

The findings and conclusions in this manuscript are those of the authors and do not necessarily represent the views of the Centers for Disease Control and Prevention and the Agency for Toxic Substances and Disease Registry.

B.-. Davids $\cdot$ S. S. Hutchins $(\varangle) \cdot$ C. P. Jones $\cdot$ J. R. Hood Centers for Disease Control and Prevention, Atlanta, GA, USA

e-mail: ssh1@cdc.gov policies, resources, and investments responsible for better health.

Keywords Community health · County-level health · Life expectancy $\cdot$ Social determinants of health $\cdot$ Race/ethnicity

\section{Introduction}

Public health professionals are concerned not only with population health status, individual risk behaviors, access to health care, and environmental hazards but also with contexts or social and structural environments of the populations they serve [1-4]. Since the 1990s, national population health goals and objectives have reflected the importance of social factors in determining health in the USA [4-6]. Healthy People 2020, a report of the latest national health goals, builds on previous healthy people reports with overarching goals, such as creating social and physical environments that promote good health and achieving health equity and eliminating health disparities. In the report, there is a new topic area devoted to social determinants of health [4].

In Healthy People 2020, social determinants of health are defined as the conditions in which people are born, live, learn, work, play, worship, and age [4]. They are part of a framework and are considered the "causes of the causes" and "unnatural causes" that give rise to individual health behaviors, health outcomes and syndemics [7-9]. A major reason for disparities in health status between US populations regardless of advances in prevention, diagnosis, and treatment is social structures and conditions, although policymaking, health services, individual behavior, biology, and genetics are important factors in determining health [4, 7-13]. In 2008, the World Health Organization's Commission on Social Determinants of Health concluded that social conditions are the single most influential 
determinant of gaps in health status between segments of the population and outlined recommendations on closing the gap in a generation by addressing social determinants of health $[14,15]$.

In response to the 2008 Commission report and a 2009 World Health Assembly resolution WHA62.14 on "Reducing Health Inequities through Action on the Social Determinants of Health [16]," the World Health Assembly convened a World Conference on the Social Determinants of Health [17]. A key action step articulated at the conference is to monitor health inequities and identify and assess policies for improving health.

In the USA, monitoring health inequities primarily focuses on populations, states, and neighborhoods with limited examination by county where decisions are made about policy implementation [7, 18-41]. For example, population-based studies demonstrate that education, income, and poverty are linked to various health outcomes, including life expectancy $[7,24]$. Health outcomes have been found to be graded by the level of these social determinants [7, 24]. Neighborhood studies at the census tract level consistently show links between low socioeconomic status or composition of racial and ethnic minority populations and health inequalities [25-37]. In addition, a geographic study of service planning areas and health districts in Los Angeles County shows that the lowest income areas have the highest homicide rates and lowest projected life expectancy [21]. Recently published county-level studies show that various social factors are linked to life expectancy, cardiovascular diseases, diabetes prevalence and age at diagnosis, and HIV diagnosis [38-42]. These studies suggest that social conditions affect health status at the county level and are influenced by county- level structural, economic, political, educational, health care, and physical environmental policies. The present study seeks to provide a recent analysis of countylevel life expectancy and social determinants of health for all US counties to (1) assess current health inequities and (2) discuss policy implications and opportunities for improving community health.

\section{Methods}

Study Design, Population, and Data Sources

A national ecological study of all 3,141 US counties or county equivalents (from all 50 states and the District of Columbia) was conducted to examine disparities and relationships between social determinants of health and health status indicators such as life expectancy. County-level social determinants and health status indicators were obtained from the 2009 Community Health Status Indicators (CHSI) dataset [43]. The dataset is an online publicly available collection of demographic information; social, health status, behavioral and healthcare indicators; and environmental exposures by county obtained from various national cross-sectional surveys, and vital statistics obtained from the US Census Bureau and Department of Health Human Services. Definitions for CHSI measures are described in detail elsewhere [43]. Data were typically from surveys either conducted during in-person interviews or by telephone [43]. Demographic data on county population size, density, ages, and social factors (poverty level and race/ethnicity as defined using OMB standards) were obtained from the Current Population Survey (CPS) [43]. The CPS is a monthly survey of households conducted by the Bureau of Census for the Bureau of Labor Statistics. The CPS collects data on demographic, social and economic characteristics of the US population and provides county-level estimates. Health status and outcome data were primarily obtained from the Behavioral Risk Factor Surveillance System (BRFSS) and the National Vital Statistics System (NVSS).

\section{Social Determinants (Social Indicators)}

Of available social indicators in the CHSI dataset, three most commonly studied social determinants were examined by county: poverty, education, and race/ethnicity. Socioeconomic status (SES) indicators (poverty and education) were defined as the percentage (prevalence) of residents in a county who lived below the federal poverty level and percentage (prevalence) of adults aged 25 years who had not graduated from high school (no high school diploma). The percentage of residents living below the federal poverty level was computed using the number of residents living below the poverty level in a county in 2008 divided by the midyear 2008 county population. To compute the prevalence of the adult population without a high school diploma in the county, the number of adults aged 25 years or older in 2000 (available in the CHSI dataset) was divided by the midyear 2008 county population of adults aged 19 years of age or older; admittedly, an underestimate of the prevalence without a high school diploma in the county. The chosen denominator was the closest adult age grouping available in the CHSI dataset [43]. Racial indicators were defined as the percentage of White American residents or the percentage of African-American residents in the county [43]. Percentages of White Americans and African Americans were computed by dividing the self-reported number of whites or African Americans in the county by their midyear 2008 county population [43]. Social indicators of poverty, education, and race/ethnicity were available for essentially all the US counties or county equivalents (Table 1). Although percentages of Hispanic, Asian, and American Indian/Alaska Native populations were available in the CHSI dataset, correlations of life expectancy with percentages of these populations had limited variability, which precluded meaningful analyses. For example, modest correlation coefficients were 
Table 1 Characteristics of counties, the USA, 2009 community health status indicators dataset

\begin{tabular}{|c|c|c|c|}
\hline Characteristics & $\begin{array}{l}\text { Total } \\
\text { counties }^{\mathrm{a}}\end{array}$ & Median & Range \\
\hline \multicolumn{4}{|l|}{ Demographics } \\
\hline Population size (persons) & 3,141 & 25,546 & $42-9,862,049$ \\
\hline \multicolumn{4}{|l|}{ Population density } \\
\hline $\begin{array}{l}\text { Number of persons per square } \\
\text { mile }\end{array}$ & 3,140 & 44 & $0-71,202$ \\
\hline \multicolumn{4}{|l|}{ Age (years; \%) } \\
\hline$<19$ & 3,141 & 24 & $0-43$ \\
\hline $19-64$ & 3,141 & 60 & $48-84$ \\
\hline $65-84$ & 3,141 & 13 & $3-29$ \\
\hline$\geq 85$ & 3,141 & 2 & $0-11$ \\
\hline \multicolumn{4}{|l|}{ Social indicators } \\
\hline Living below poverty level (\%) & 3,140 & 14 & $3-54$ \\
\hline No high school diploma (\%) & 3,141 & 19 & $3-89$ \\
\hline White Americans (\%) & 3,141 & 93 & $6-100$ \\
\hline African Americans (\%) & 3,141 & 2 & $0-86$ \\
\hline \multicolumn{4}{|l|}{ Health indicators } \\
\hline Life expectancy (years) & 3,139 & 77 & $67-81$ \\
\hline \multicolumn{4}{|l|}{ All-causes death rate } \\
\hline Per 100,000 population & 3,139 & 1,137 & $330-3,371$ \\
\hline \multicolumn{4}{|l|}{ Homicide rate } \\
\hline Per 100,000 population & 1,182 & 7 & $1-58$ \\
\hline Hypertension (\%) & 1,522 & 26 & $7-47$ \\
\hline Obesity (\%) & 2,224 & 24 & $4-43$ \\
\hline Diabetes $(\%)$ & 2,719 & 8 & $1-21$ \\
\hline
\end{tabular}

Source: http://communityhealth.hhs.gov/homepage.aspx?j=1

${ }^{\text {a }}$ Total number less than 3,141 indicates only counties with characteristic and analyzed. All subsequent analyses with counties limited to those with the variable. No imputed data used

found between county-level life expectancy and county compositions of Hispanic $(r=0.02)$, Asian $(r=0.05)$, and American Indian and Alaska Native $(r=0.01)$ residents.

\section{Health Outcomes (Health Indicators)}

Many health outcomes were available in the CHSI dataset. Average life expectancy at birth was the main outcome variable examined and was available for 3,139 of 3,141 counties or county equivalents in the USA (Table 1). Life expectancy was derived from age-specific mortality and was subject to limitations described below. Life expectancy represented the average number of years that an infant was expected to live given 5-year, age-specific mortality rates from 1997 to 2001 $[38,43]$. Other health outcomes examined were age-adjusted death rates due to all causes (per 100,000 population) and to homicide (per 100,000 population). Morbidity indicators examined were prevalence of hypertension, obesity and diabetes. The all-causes death rate was computed using agespecific rates derived from the number of deaths from 1996 to 2005 from the NVSS and the best available population estimate for each year between 1996 and 2005 and then age adjusted to the 2000 standardized population [43]. Whether the number of deaths for the entire 10-year period was used in the computation depended on the county population size. County-specific death rates were only reported in the CHSI dataset if at least 10 deaths were reported in the county [43]. The homicide rate was defined as the number of relevant assaults divided by county population and age adjusted to the 2000 standardized population [43]. Assaults were defined as those obtained from reports with ICD9 codes E960-E969 and ICD-10 codes U01-U02, X85-X99, Y00-Y09, and Y87.1. The homicide rate was available in approximately one third of the 3,141 counties (Table 1). Prevalence of hypertension, obesity and diabetes were obtained from the BRFSS conducted from 2000 to 2006 with varying availability by county (Table 1) [43]. Obesity was defined as the percentage of adults with a body mass index (BMI) of 30 or greater. BMI was computed from self-reported weight in pounds (multiplied by 703) divided by self-reported height (in inches) squared. Hypertension was defined as the percentage of adults who responded "yes" to the question "Have you ever been told by a doctor, nurse or other health professional that you have high blood pressure?" Diabetes was defined as the percentage of adults who responded "yes" to the question "Have you ever been told by a doctor that you have diabetes?"

\section{Statistical Methods}

Univariate, bivariate and multivariate analyses were performed using SAS, version 9.2. Counties with missing variables were excluded from further analyses of the missing variable. Univariate frequency distributions were examined to describe county characteristics. Correlation analyses were main bivariate methods performed to examine the association between life expectancy and social and health indicators. Analyses of variance was the statistical method performed to judge statistical significance $(p<0.05)$. As the linear association was strongest for SES indicators, we examined if poverty and education modified the relationship between life expectancy and race by stratifying counties into quartiles by poverty and education. To further assess if social indicators were independently associated with life expectancy, multivariate linear regression models were examined. Only health indicators exhibiting moderate to strong relationships $(r>=0.55)$ with life expectancy in bivariate analyses were included in another multivariate linear regression model with social indicators (i.e., all-causes death rate, homicide rate and prevalences of hypertension, obesity, and diabetes). Multivariate models were fitted using backward elimination and tested for multicollinearity using condition indices and variance 
decomposition proportions adjusted for interacting and confounding covariates. Statistically significant multicollinearity was present among adjusted social and health indicators and the variable measuring the percentage of White Americans in a county in both the multivariate model with only social indicators and the full model with social and health indicators together. As such, the variable measuring percentage of the white population in a county was dropped from multivariate models and could not be examined further. Therefore, other social indicators (education and poverty) were expected to measure the effect of the white population in the county. Details of multivariate models will be provided on request.

\section{Results}

Among the 3,141 US counties, the median population size was 25,546 residents. Population sizes ranged from 42 to $9,862,049$ residents (Table 1). One half of the counties had a population density of more than 44 residents $/ \mathrm{mi}^{2}$. Across counties, there were disparities by social and health indicators (Table 1, see ranges). For one half of the counties, more than $60 \%$ of residents were 19-64 years of age. One half of the counties had more than $19 \%$ of adults with no high school diploma, $14 \%$ of residents who lived below the federal poverty level, $93 \%$ of residents who reported being White Americans or $2 \%$ of residents who reported being African Americans. One half of the counties had an average life expectancy at less than 77 years, age-adjusted death rate due to all causes more than 1,136 deaths per 100,000 population, age-adjusted homicide rate more than 7 per 100,000 population and adult hypertension prevalence of more than $26 \%$, obesity prevalence of more than $24 \%$, and diabetes prevalence of more than $8 \%$.

Of the four social indicators examined, three showed a negative or inverse linear correlation with life expectancy (Fig. 1). As the percentage of residents in the county who lived below the poverty level increased, life expectancy decreased $(r=-0.65 ; P<0.05)$. Similarly, as the percentage of the county's adults with no high school diploma increased or as the percentage of the African American population increased, life expectancy decreased $(r=-0.64 ; P<0.05$ and $r=-0.56$; $P<0.05$, respectively). In contrast, there was a positive or direct linear correlation between life expectancy and the percentage of the county's resident population who were white. For example, as the percentage of the resident white population in the county increased, life expectancy also increased $(r=+0.51 ; P<0.05)$. Correlations between life expectancy and racial composition were linear (Fig. 1).

Counties grouped in the same stratum (a quartile) by percentage of residents who lived in poverty or adults without a high school diploma, maintained a similar direction of the correlation between life expectancy and race (Tables 2 and 3).
A positive correlation was consistently found between the percentage of white residents in the county and life expectancy. A negative correlation was also consistently found between the percentage of African American residents and life expectancy in the county. In addition, the strength of these relationships varied by stratum. As the prevalence of the county population that lived in poverty or of adults with no high school diploma increased, the larger the linear correlation coefficient $(r)$ between county life expectancy and racial composition.

In the multivariate model of social factors only (model 1) (Table 4), a significant interaction occurred among the following variables: (1) percentage of residents who lived in poverty and percentage of African Americans $(b=0.002 ; P<0.001)$ and (2) percentage of adults with no high school diploma and percentage of African Americans $(b=0.001 ; P<0.001)$. As mentioned previously, the percentage of White Americans in the county was not examined with other variables because of multicollinearity with education and income. No confounders were identified and included in this model limited to social indicators only. In a full model with social and health indicators together (model 2), significant interaction occurred again between variables measuring the percentage of residents living in poverty and percentage of African Americans $(b=$ 0.002; $P<0.001)$ and percentage of adults with no high school diploma and percentage of African Americans $(b=-0.002$; $P<0.001$ ). In addition, interaction also occurred with variables measuring percentage of African Americans and adult prevalence of diabetes $(b=0.004 ; P<0.001)$. The prevalence of adults with hypertension was independently and negatively correlated with life expectancy in the full model (model $2 ; b=$ $-0.052 ; P<0.001)$. As the prevalence of hypertension in the county increased, life expectancy decreased regardless of the presence of social indicators and diabetes.

\section{Discussion}

This is the most up-to-date assessment of life expectancy disparities across all US counties or county equivalents that show a linear link with county adult educational attainment, resident population in poverty and White or African-American compositions. These linear or dose-response relationships between life expectancy and social indicators support a linkage between longevity and social factors. This ecologic study captures both individual and population characteristics in the county and the interaction of individuals and populations with the county environment or conditions. Disparities in socioeconomic factors across counties linked to disparities in county life expectancy likely explain the lack of progress in US life expectancy. If we exclude the 1918-1919 influenza pandemic, life expectancy in the USA had increased for more than 100 years until 1983 [44]. Adverse economic conditions in a 
Fig. 1 Correlation of life expectancy and selected social indicators, US counties, 2009 community health status indicators dataset
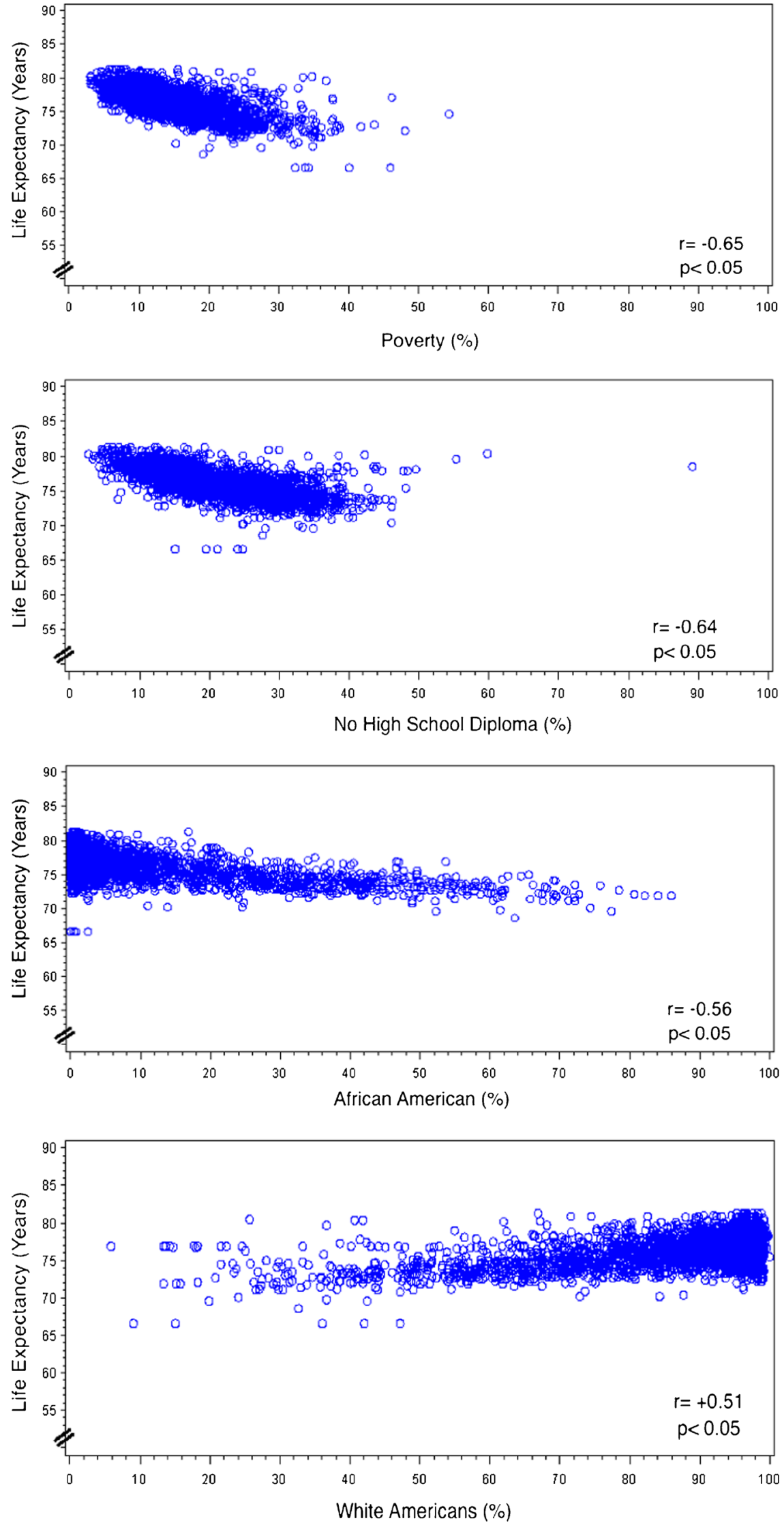

$r=$ correlation coefficient 
Table 2 Correlation of life expectancy and racial composition by residents living in poverty, US counties, 2009 community health indicators dataset

\begin{tabular}{llll}
\hline $\begin{array}{l}\text { County residents } \\
\text { living in poverty } \\
(\% \text {; quartile) }\end{array}$ & $\begin{array}{l}\text { Total number } \\
\text { of counties }(n)\end{array}$ & $\begin{array}{l}\text { \% African- } \\
\text { American } \\
\text { residents }(r)\end{array}$ & $\begin{array}{l}\text { \% White- } \\
\text { American } \\
\text { residents }(r)\end{array}$ \\
\hline$<10.9$ & 778 & $-0.33^{*}$ & $+0.14^{*}$ \\
$10.9-14.29$ & 779 & $-0.38^{*}$ & $+0.30^{*}$ \\
$14.3-18.3$ & 791 & $-0.44^{*}$ & $+0.31^{*}$ \\
$>18.3$ & 791 & -0.51 & $+0.47^{*}$ \\
\hline
\end{tabular}

$r$ correlation coefficient of county life expectancy and the percentage of African-American or White-American residents

${ }^{a}$ Each stratum is a quartile of counties with indicated percentage of county residents who lived in poverty

$* P<0.01$

country are associated with lower life expectancy as shown when comparing low- to high-income countries [45, 46]. In fact, adverse business cycles in the USA have been linked to higher suicide rates since the late 1920s [47]. The 14-year difference in life expectancy across US counties, from 67 years in one county to 81 years in another county, is reflected in the median US life expectancy of 77 years, which has placed the health status of the USA near the bottom rank of developed nations in the same economic grouping $[4,45]$. To examine county health further, health rankings of individual counties within states have been made available by the Robert Wood Johnson Foundation [48].

Disparities in life expectancy are not only linked to socioeconomic characteristics but racial composition across US counties, highlighting opportunities and challenges for certain communities. Counties with a large resident population of White Americans have the longest life expectancy and those counties with the largest resident population of African Americans have the shortest life expectancy. Counties with a

Table 3 Correlation of life expectancy and racial composition by adults aged 25 years and older with no high school diploma, US counties, 2009 community health indicators dataset

\begin{tabular}{llll}
\hline $\begin{array}{l}\text { Adults with no high } \\
\text { school diploma } \\
(\%)(\text { quartile) }\end{array}$ & $\begin{array}{l}\text { Total } \\
\text { number of } \\
\text { counties }(n)\end{array}$ & $\begin{array}{l}\text { \% African- } \\
\text { American } \\
\text { residents }(r)\end{array}$ & $\begin{array}{l}\text { \% White- } \\
\text { American } \\
\text { residents }(r)\end{array}$ \\
\hline$<14.3$ & 784 & $-0.32^{*}$ & $+0.27^{*}$ \\
$14.3-18.49$ & 785 & $-0.44^{*}$ & $+0.28^{*}$ \\
$18.5-25.8$ & 784 & $-0.49^{*}$ & $+0.48^{*}$ \\
$>25.8$ & 786 & $-0.54^{*}$ & $+0.49^{*}$ \\
\hline
\end{tabular}

$r$ correlation coefficient of county life expectancy and either the percentage of African-American or White-American residents

${ }^{a}$ Each stratum is a quartile of counties with indicated percentage of adults with no high school diploma

$* P<0.01$
Table 4 Multivariate linear association between life expectancy and social and health indicators, US counties, 2009 community health status indicators dataset

\begin{tabular}{|c|c|c|}
\hline \multirow[t]{2}{*}{ County indicators } & \multicolumn{2}{|l|}{ Life expectancy } \\
\hline & $\mathrm{b}(\mathrm{SE})$ & $P$ value \\
\hline \multicolumn{3}{|l|}{ Social indicators only model ${ }^{\mathrm{a}}$} \\
\hline \multicolumn{3}{|l|}{ Model $1^{\mathrm{b}}$} \\
\hline Intercept & $80.214(0.079)$ & $<0.0001$ \\
\hline Percent living in poverty & $-0.115(0.006)$ & $<0.0001$ \\
\hline Percent with no high school diploma & $-0.084(0.005)$ & $<0.0001$ \\
\hline Percent African American & $-0.096(0.006)$ & $<0.0001$ \\
\hline \multicolumn{3}{|l|}{ Interaction $^{\mathrm{d}}$} \\
\hline $\begin{array}{l}\text { Percent poverty and percent African } \\
\text { American }\end{array}$ & $0.002(0.0003)$ & $<0.0001$ \\
\hline $\begin{array}{l}\text { Percent no high school diploma } \\
\text { and percent African American }\end{array}$ & $0.001(0.0003)$ & $<0.05$ \\
\hline \multicolumn{3}{|l|}{ Full model $^{\mathrm{a}}$} \\
\hline \multicolumn{3}{|l|}{ Model $2^{\mathrm{c}}$} \\
\hline Intercept & $82.295(0.171)$ & $<0.0001$ \\
\hline Percent living in poverty & $-0.117(0.009)$ & $<0.0001$ \\
\hline Percent with no high school diploma & $-0.056(0.007)$ & $<0.0001$ \\
\hline Percent African American & $-0.092(0.010)$ & $<0.0001$ \\
\hline Percent with hypertension & $-0.052(0.007)$ & $<0.0001$ \\
\hline Percent with diabetes & $-0.144(0.021)$ & $<0.0001$ \\
\hline \multicolumn{3}{|l|}{ Interaction $^{\mathrm{d}}$} \\
\hline $\begin{array}{l}\text { Percent living in poverty and percent } \\
\text { African American }\end{array}$ & $0.002(0.0005)$ & 0.0002 \\
\hline $\begin{array}{l}\text { Percent no high school diploma and } \\
\text { percent African American }\end{array}$ & $-0.001(0.0005)$ & 0.0278 \\
\hline $\begin{array}{l}\text { Percent African American and percent } \\
\text { diabetes }\end{array}$ & $0.004(0.0014)$ & 0.0081 \\
\hline
\end{tabular}

$B$ parameter estimate, $S E$ standard error of parameter estimate

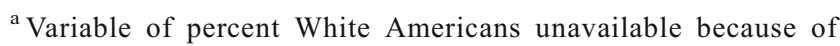
collinerarity with income and educational attainment variables

${ }^{\mathrm{b}}$ Only include variables for poverty, educational attainment, and AfricanAmerican composition

${ }^{\mathrm{c}}$ All variables in model 1 plus variables for health conditions (high blood pressure and diabetes)

${ }^{\mathrm{d}}$ Interaction variables, beta coefficient, or slope varied across the indicated variables

mixture have a life expectancy in the middle range. The positive association of longer life in counties with the largest white population is sustained across counties with different proportions of residents living in poverty and adults without a high school diploma. Similarly, the negative linear relationship between life expectancy and African-American composition also persists in counties with the same level of poverty and educational attainment. The variable "race" is a rough proxy for social class, rougher for culture, and meaningless for genes, but "race" precisely captures the social classification of people in a race-conscious society [49]. As such, "race" captures the impacts of racism on individual and community 
health and well being $[49,50]$. Indeed, being perceived by others as White is associated with health advantages, even for those who self-identify with a non-White group [51]. Researchers describe racial and income segregation as important causes of health disparities which have health consequences for both African Americans and for White Americans [52].

Many findings in the present study are consistent with studies of populations and different geographic units or locations [7, 18-42]. In population and geographic studies, the best health outcome are among US populations and locations with the best socioeconomic status or with the largest white or Asian compositions [7, 18-42], while the worst life expectancy is consistently in populations and areas with the lowest socioeconomic status and mostly of African-American composition even at income and educational levels similar to the white population [7, 18-39]. Income and racial and ethnic inequalities at the population- and geographic level indicate that more is needed to improve the health status of certain lowincome and minority populations and communities as does the present study. The dual strategy used to achieve record high early childhood vaccination and reduction or elimination of many early childhood vaccination disparities among racial and ethnic minority children compared with white children and children living in the highest risk geographic areas compared with other geographic areas is an example of use of effective, evidence-based interventions [53, 54] to reach also vulnerable populations and communities. To date, the impact of the dual strategy has been sustained for nearly two decades. Because social conditions are not the same for the most vulnerable populations and communities, the dual strategy has applied not just a universal set of interventions but also targeted interventions by population and high-risk communities to reach vulnerable, low income, and minority children $[53,54]$.

To identify targeted interventions or polices likely to work in counties with a worse life expectancy, policies that currently exist in counties with the better life expectancy can be examined. County-level analyses were chosen in the present study because counties (although they vary by state ( 48 of the 50 states have operational county governments)), translate local, state, and federal policies into services for education, employment and income, social programs, public health, health care, transportation, recreation, resources, and investments [55]. The healthiest (best or better life expectancy) US counties could be examined further to identify the economic, educational, physical environmental, social relationships, health care and health promotion policies, structures, resources, and investments that explain why their population lives longer than populations in other counties. County-level studies can provide clues about community policies that may be responsible for good overall community health and the health of individuals in those communities [56, 57]. The best health counties having favorable social determinants of health can serve as sentinel geographic locations of good community health. For example, comparisons of state- and district-level educational policies by high school graduation rates describe a "formula for success" when schools are fully resourced with talented, caring teachers, well-trained and numerous support staff, protective and supportive administrators, challenging curricula, high expectations of success for all students, libraries, an adequate supply of textbooks, computers, art and music programs, and science labs [58]. Policy research on counties with the best community health status can assist in supporting national initiatives to reduce health disparities and achieve health equity [4, 59-61]. In addition to questions about educational policies and financial investments that lead to success as outlined above, questions about employment, housing and the built and physical environments could provide clues about interventions likely to be effective in improving community health in counties with low life expectancy.

Adverse county-level disparities and inequities in life expectancy associated with racial composition, educational attainment and poverty should be amenable to policy changes that favor long life. To reduce health inequities and improve health status for all in the USA, there is a call for action using comprehensive approaches to address both social determinants and access to quality health care together through evidence-based, intersectoral programs such as the National Prevention Strategy $[59,60]$. If many more public health and healthcare professionals and their intersectoral partners are aware that US county-level life expectancy disparities have grown since 1983, with no improvement in life expectancy from 1983 to 1999 and an actual decline in life expectancy for many counties, intersectoral actions encouraged by many national initiatives [4, 59-62] may be more fully implemented.

The relationship between county African American composition and life expectancy varying by education, poverty, and diabetes when examined together are new to public health research and reflects our ability to examine multiple variables together unlike the other population and neighborhood studies in which multivariate analyses were not consistently performed [7, 24-32]. Our findings in the present study highlight the importance of not only examining income, educational attainment and health outcomes or race/ethnicity and health outcomes but all indicators together (income, education, race, and health) in support of many researchers who stress the importance of examining both social class and race/ethnicity together [7, 22, 63, 64]. Links between poverty, educational attainment or diabetes with life expectancy in the multivariate analysis all depend or vary by the prevalence of African-American residents in a county. However, hypertension seems to exert an effect on life expectancy independent or regardless of educational attainment, poverty, racial composition, or diabetes in counties examined. 
Limitations and Strengths

The present study is subject to some limitations. Because many of the data sources are from cross-sectional studies, we were only able to assess an association and not causation, although the dose-response relationships support causal relationships [65]. Other criteria for causation include strength, consistency, specificity, temporality, biologic plausibility, coherence, experimental evidence, and analogy of the association. In addition, the percentage of adults in a county without a high school diploma is likely underestimated, because the denominator (adults 19 years of age or older) for computation of the percentage had a larger population than the ideal denominator (adults 25 years of age or older). Other limitations include the inability to examine life expectancy beyond 2001, an assessment of life expectancy and county composition of other racial and ethnic populations, morbidity using physician diagnoses from a telephone survey (the Behavioral Risk Factor Surveillance System), multivariate examination of the white composition of the county with other social and health indicators and lack of health indicators for all US counties such as prevalence of hypertension, diabetes, and obesity and the homicide rate. More current life expectancy estimates by counties after 2001 have not been available to the developers of the 2009 CHSI dataset [43]. County-level demographic data from the American Community Survey (ACS) were also unavailable to the CHSI developers who have compiled demographic and health data together in one dataset. ACS data became available in 2010 and 2011 and could be used in the future. It is unclear whether county-level disparities in life expectancy today are worse, the same or better now. However, with more people living in poverty now [66], life expectancy disparities may have worsened. Indicators for hypertension, diabetes and obesity were only available among counties that collected this information which was not at random. In addition, self-reported prevalence estimates of hypertension and diabetes from a telephone survey may be subject to recall bias and exclude low-income households that only use cell phones, which underestimate the prevalence of these chronic conditions in a county [67]. Multivariate analysis that included health indicators (full model) was limited to a fraction of all counties because those heath data were only available among a fraction of counties. These counties were not randomly selected.

Despite these limitations, this study has several strengths. It is a national study of all US counties or equivalents, shows linear correlations or dose-response relationships that support causal relationships between life expectancy and educational attainment, poverty and race, and has been able to adjust for effect modifiers in assessing whether individual social determinants of health examined are affecting life expectancy alone, together, or with other health outcomes. Our findings are consistent with many other studies at the population and county levels [7, 18-42]. These studies and our findings taken together strengthen the likelihood that social indicators by county are linked to life expectancy across counties.

\section{Conclusions}

Lack of progress in life expectancy disparities has placed the USA at the bottom of the health status list of similarly economically developed nations [4]. Policy research at the county or community level that examines communities with best health outcomes not only demonstrates the feasibility of achieving a better health status in the USA or "proof of principle" but also points to plausible models for achieving better health for all using a US approach. These "best health" communities are likely to expand our knowledge beyond differences in racial composition to solutions that address differential policies, resources and investments in US communities [47].

Acknowledgments The authors acknowledge the assistance they received from the Public Health Institute, Morehouse College, and the Institute's Director, Dr. Cynthia Trawick in providing a student researcher.

Financial Disclosure The authors have no financial disclosure or conflicts of interest.

\section{References}

1. Institute of Medicine. The future of public health. Washington, DC: The National Academies; 1988.

2. Institute of Medicine. The future of the public's health. Washington, DC: The National Academies; 2000.

3. Rosen G. A history of public health. New York: MD Publications; 1958.

4. U.S. Department of Health and Human Services. Healthy People 2020 Topics and Objectives. Available at: http://healthypeople.gov/ 2020/default.aspx. Accessed 27 September 2012.

5. U.S. Department of Health and Human Services, Public Health Service. Healthy People 2000. National health promotion and disease prevention objectives. Washington, DC: U.S. Government Printing Office; 1991.

6. U.S. Department of Health and Human Services. Healthy People 2010 Final Review. Washington, D.C.: U.S. Government Printing Office. 2011. Available at: http://www.cdc.gov/nchs/data/ hpdata2010/hp2010 final review.pdf. Accessed 27 September 2012.

7. Braveman PA, Egerter SA, Mockenhaupt RE. Broadening the focus the need to address the social determinants of health. Am J Prev Med. 2011;40(1S1):S4-18.

8. National Association of County and City Health Officials (NAAC HO). Unnatural Causes: is inequality making us sick? Available at: http://www.unnaturalcauses.org/about_the_series.php. Accessed 21 November 2013.

9. Milstein B. Hygeia's Constellation: Navigating Health Futures in a Dynamic and Democratic World [Doctoral Dissertation]. Graduate College of Interdisciplinary Arts and Sciences, Union Institute \& University: Cincinnati, OH. 2006. Available at: http://www.uic.edu/ 
sph/phtpg/Content/Reading\%20Room/Articles/Hygeia\%27s constellation_Milstein.pdf. Accessed 21 November 2013.

10. Centers for Disease Control and Prevention. Establishing a Holistic Framework to Reduce Inequities in HIV, Viral Hepatitis, STDs, and Tuberculosis in the United States. Atlanta (GA): U.S. Department of Health and Human Services, Centers for Disease Control and Prevention; October 2010. Available at: http://www.cdc.gov/ socialdeterminants/docs/SDH-White-Paper-2010.pdf. Accessed 27 September 2012.

11. Kanjilal S, Gregg EW, Cheng YJ, et al. Socioeconomic status and trends in disparities in four major risk factors for cardiovascular diseases among U.S. adults, 1971-2002. Arch Intern Med. 2006;166(21):2348-55.

12. De Walque D. Education, Information, and smoking decisions, evidence from smoking histories, 1940-2000. Washington DC: The World Bank 2004 July 2004. World Bank Policy Research Working Paper No. 3362.

13. Pierce JP, Fiore MC, Novontny TE, Hatziandreu EJ, Davis RM. Trends in cigarette smoking in the U.S. projections to the year 2000. J Am Med Assoc. 1989;261(1):61-5.

14. World Health Organization. Closing the Gap in a Generation: Health Equity through Action on the Social Determinants of Health. Report from the Commission on the Social Determinants of Health. Geneva: WHO; 2008.

15. Satcher D. Include a social determinants of health approach to reduce health inequities. Public Health Reports 2010; Suppl 4:6-7.

16. World Health Organization. World Health Assembly closes with resolutions on public health. 22 May 2009. Geneva:WHO, 2009. Available at: http://apps.who.int/gb/ebwha/pdf_files/WHA62-REC1/ WHA62_REC1-en.pdf. Accessed 27 September 2012.

17. World Health Organization. Report of Department of Ethics, Equity, Trade and Human Rights. World Conference on Social Determinants of Health. Geneva:WHO, 2011. Available at: http://www.who.int/ sdhconference. Accessed September 27, 2012.

18. Datta GD, Subramanian SV, Collditz GA, Kawachi I, Plamer JR, Rosenberg L. Individual, neighborhood, and State-level predictors of smoking among U.S. Black women: a multilevel analysis. Soc Sci Med. 2006;63(4):1034 44.

19. Lynch JW, Kaplan GA, Salone JT. Why do poor people behave poorly? Variation in adult health behaviors and psychosocial characteristics by stages of the socioeconomic lifecourse. Soc Sci Med. 1997;44(6):809-19.

20. Yen IH, Syme SL. The social environment and health: a discussion of the epidemiologic literature. Annu Rev Public Health. 1999;20:287308.

21. Redelings M, Lieb L, Sorvillo F. Years off your life? The effects of homicide on life expectancy by neighborhood and race/ethnicity in Los Angeles County. J Urban Health Bull N Y Acad Med. 2010;87:4.

22. McLaughlin D, Stokes S. Income inequality and mortality in US Counties: does minority racial concentration matter? Am J Public Health. 2002;92:1.

23. Galea S, Tracy M, Hoggatt K, DiMaggio C, Karpati A. Estimated deaths attributable to social factors in the United States. Am J Public Health. 2011;101(8):1456-65.

24. Braveman P, Cubbin C, Egerter S et al. Socioeconomic disparities in health in the United States: what the patterns tell us. Am J Public Health 2010;(Suppl 1):S186-S196.

25. Krieger N, Waterman PD, Chen JT, Rehkopf DH, Subramanian SV. Geocoding and monitoring US socioeconomic inequalities in health: an introduction to using area-based socioeconomic measures - The Public Health Disparities Geocoding Project monograph. Boston, MA: Harvard School of Public Health. Available at: http://www. hsph.harvard.edu/thegeocodingproject/. Accessed 27 September 2012.

26. Krieger N, Chen JT, Waterman PD, Rehkopf DH, Subramanian SV. Painting a truer picture of US socioeconomic and racial/ethnic health inequalities: the Public Health Disparities Geocoding Project. Am J Public Health. 2005;95:312-23.

27. Krieger N, Chen JT, Waterman PD, Rehkopf DH, Subramanian SV. Race/ethnicity, gender, and monitoring socioeconomic gradients in health: a comparison of area-based socioeconomic measures-The Public Health Disparities Geocoding Project. Am J Public Health. 2003;93:1655-71.

28. Krieger N, Chen JT, Waterman PD, Soobader M-J, Subramanian SV, Carson R. Choosing area-based socioeconomic measures to monitor social inequalities in low birthweight and childhood lead poisoningThe Public Health Disparities Geocoding Project (US). J Epidemiol Community Health. 2003;57:186-99.

29. Krieger N, Waterman PD, Chen JT, Soobader M-J, Subramanian SV. Monitoring socioeconomic inequalities in sexually transmitted infections, tuberculosis, and violence: geocoding and choice of area-based socioeconomic measures-The Public Health Disparities Geocoding Project (US). Public Health Rep. 2003;118:240-60.

30. Krieger N, Chen JT, Waterman PD, Soobader M-J, Subramanian SV, Carson R. Geocoding and monitoring US socioeconomic inequalities in mortality and cancer incidence: does choice of area-based measure and geographic level matter?-The Public Health Disparities Geocoding Project. Am J Epidemiol. 2002;156:471-82.

31. Krieger N, Waterman P, Chen JT, Soobader M-J, Subramanian SV, Carson R. ZIP Code caveat: bias due to spatiotemporal mismatches between ZIP Codes and US census-defined areas - The Public Health Disparities Geocoding Project. Am J Public Health. 2002;92:1100-2.

32. Krieger N, Waterman P, Lemieux K, Zierler S, Hogan JW. On the wrong side of the tracts? Evaluating the accuracy of geocoding in public health research. Am J Public Health. 2001;91:1114-6.

33. Subramanian SV, Chen JT, Rehkopf DH, Waterman PD, Krieger N. Neighborhood disparities in context: multilevel analysis of census tract variations in black excess mortality and poverty. Am J Public Health. 2005;95:260-5.

34. Krieger N. A century of census tracts: health and the body politic (1906-2006). J Urban Health. 2006;83:355-61.

35. Subramanian SV, Chen JT, Rehkopf DR, Waterman PD, Krieger N. Comparing individual and area-based socioeconomic measures for the surveillance of health disparities: a multilevel analysis of Massachusetts births, 1988-92. Am J Epidemiol. 2006;164:823-34.

36. Rehkopf DH, Haughton L, Chen JT, Waterman PD, Subramanian SV, Krieger N. Monitoring socioeconomic disparities in death: comparing individual-level education and area-based socioeconomic measures. Am J Public Health. 2006;96:2135-8.

37. Chen JT, Rehkopf DH, Waterman PD, Subramanian SV, Coull BA, Cohen B, et al. Mapping and measuring social disparities in premature mortality: the impact of census tract poverty within and across Boston neighborhoods, 1999-2001. J Urban Health. 2006;83:106385. doi:10.1007/s11524-006-9089-7.

38. Murray CJL, Kulkarni SC, Michaud C, Tomijima N, Bulzacchelli MT, et al. Eight Americas: investigating mortality disparities across races, counties, and race-counties in the United States. PLOS Medicine; 200X:e260. Available at: http://www.plosmedicine.org/ article/info:doi/10.1371/journal.pmed.0030260. Accessed 27 September 2012.

39. Hendryx M, Zullig KJ. Higher coronary heart disease and heart attack morbidity in Applaachian coal mining regions. Prev Med. 2009;49: 355-9.

40. Barker LE, Kirtland KA, Gregg EW, et al. Geographic distribution of diagnosed diabetes in the US: a diabetes belt. Am J Prev Med. 2011:40:434-9.

41. Barker L, Gerzoff R, Crespo R, Shrewsberry M. Age at diagnosis of diabetes in Appalachia. Popul Health Metrics. 2011;9:54.

42. Song R, Hall I, McDavid Harrison K, et al. Identifying the impact of social determinants of health on disease rates using correlation analysis of area-based summary information. Public Health Rep. 2011;126 Suppl 3:70-80. 
43. US Department of Health and Human Services. Community Health Status Indicators, CHSI 2009. Available at: http://communityhealth. hhs.gov/homepage.aspx?j=1. Accessed 27 September 2012.

44. Institute of Medicine. Challenges and successes in reducing health disparities: workshop summary. Washington, DC: The National Academies; 2008.

45. Bezruchka S. The Hurrider I Go the Behinder I Get: The Deteriorating International Ranking of U.S. Health Status. Annu Rev Public Health. 2012;33:157-73.

46. Bezruchka S. The effect of economic recession on population health. Can Med J. 2009. doi:10.1503/cmaj.090553.

47. Luo F, Florence CS, Quispe-Agnoli M, et al. Impact of business cycles on US suicide rates, 1928-2007. Am J Public Health. 2011;101:1139-46.

48. Robert Wood Johnson Foundation. County health rankings and roadmaps: a healthier nation, county by county. Available at: http:// www.countyhealthrankings.org. Accessed 14 November 2013.

49. Jones CP. "Race", racism, and the practice of epidemiology. Am J Epidemiol. 2001;154(4):299-304.

50. Jones CP. Levels of racism: A theoretic framework and a Gardener's Tale. Am J Public Health. 2000;90(8):1212-15.

51. Jones C, Truman BI, Elam-Evans LD, Jones CA, Jones CY, Jiles R, Rumisha SF, Perry GS. Using "socially assigned race" to probe white advantages in health status. Ethn Dis. 2008;18(4):496-504.

52. Williams DR, Jackson PB. Social sources of racial disparities in health. Health Aff. 2005;24(2):325-34.

53. Williams WW, Hutchins SS, Orenstein WA, Rodewald L. Immunization and preventive care. In: Satcher D, Pamies RR, editors. Multicultural medicine and health disparities. New York, NY: McGraw-Hill; 2006. p. 233-49.

54. Hutchins SS, Jiles R, Bernier R. Elimination of measles and of disparities in measles childhood vaccination coverage among racial and ethnic minority populations in the United States. J Infect Dis. 2004;189:S146-52.

55. National Association of Counties. Overview of County Government. Available at: http://www.naco.org/counties/pages/overview.aspx.

56. Dalgard OS, Tambs K. Urban environment and mental health: a longitudinal study. Br J Psychiatry. 1997;171:530-6.
57. Institute of Medicine. State and Local policy initiatives to reduce health disparities: workshop summary. Washington, DC: The National Academies; 2011.

58. Schott Foundation for Public Education. Given Half a Chance: The Schott 50 State Report on Public Education and Black Males, 2008. Available at: http://blackboysreport.org/. Accessed 27 September 2012.

59. Koh HK, Oppenheimer SC, Massin-Short SB, Emmons KM, Geller $\mathrm{AC}$, Viswanath $\mathrm{K}$. Translating research evidence into practice to reduce health disparities: a social determinants approach. Am J Public Health 2010; Supplement 1:S72-S80.

60. National Prevention Council 2010. National Prevention Strategy. Available at: http://www.healthcare.gov/prevention/nphpphc/ strategy/report.pdf. Accessed 27 September 2012.

61. U.S. Department of Health and Human Services HHS Action Plan to Reduce Racial and Ethnic Disparities. Available at: http:// minorityhealth.hhs.gov/npa/templates/content.aspx?lvl=1\&lvlid= 33\&ID=285. Accessed 27 September 2012.

62. U.S. Department of Health and Human Services. National Stakeholders Strategy for Achieving Health Equity. Available at: http://minorityhealth.hhs.gov/npa/templates/content.aspx?lvl= 1\&lvlid=33\&ID=286. Accessed 27 September 2012.

63. Krieger N, Queensberry C, Peng T, et al. Social class, race/ethnicity, and incidence of breast, cervix, colon, lung, and prostate cancer among Asian, black, Hispanic, and white residents of the San Francisco Bay area, 1988-92 (United States). Cancer Causes Control. 1999;10:525-37.

64. Barbeau EM, Krieger N, Soobader M. Working class matters: socioeconomic disadvantage, race/ethnicity, gender, and smoking in NHIS 2000. Am J Public Health. 2004;94:269-78.

65. Rothman KJ and Greenland S (eds.). In: Modern Epidemiology, 2nd edn. Philadelphia, PA: Lippincott Williams and Wilkins; 1998, pp 24-27.

66. U. S. Census Bureau. Income, Expenditures, Poverty, \& Wealth: Poverty. Available at: http:/www.census.gov/compendia/statab/cats/ income_expenditures_poverty_wealth.html. Accessed 27 September 2012.

67. Centers for Disease Control and Prevention. Methodological changes in the Behavioral Risk Factor Surveillance System in 2011 and potential effects on prevalence estimates. MMWR 2012; 61:410-413. 